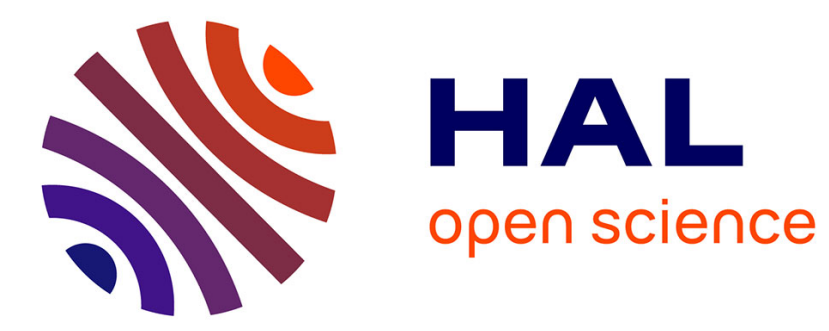

\title{
Dry Machining of Inconel 718, Workpiece Surface Integrity
}

\author{
A. Devillez, Gael Le Coz, Serge Dominiak, Daniel Dudzinski
}

\section{To cite this version:}

A. Devillez, Gael Le Coz, Serge Dominiak, Daniel Dudzinski. Dry Machining of Inconel 718, Workpiece Surface Integrity. Journal of Materials Processing Technology, 2011, 211 (10), pp.1590-1598. 10.1016/j.jmatprotec.2011.04.011 . hal-03046094

\section{HAL Id: hal-03046094 \\ https://hal.univ-lorraine.fr/hal-03046094}

Submitted on 8 Dec 2020

HAL is a multi-disciplinary open access archive for the deposit and dissemination of scientific research documents, whether they are published or not. The documents may come from teaching and research institutions in France or abroad, or from public or private research centers.
L'archive ouverte pluridisciplinaire HAL, est destinée au dépôt et à la diffusion de documents scientifiques de niveau recherche, publiés ou non, émanant des établissements d'enseignement et de recherche français ou étrangers, des laboratoires publics ou privés.

\section{(ㅇ)(1) $\$$}

Distributed under a Creative Commons Attribution - NonCommercial - NoDerivatives $\mid 4.0$ 


\title{
Title : $\quad$ Dry Machining of Inconel 718, Workpiece Surface Integrity
}

Authors : $\quad$ A. Devillez, G. Le Coz, S. Dominiak, D. Dudzinski

Affiliation: Laboratoire d'Etudes des Microstructures et de Mécanique des Matériaux, UMR CNRS No. 7239,

Université de Metz, Ile du Saulcy, 57045, Metz, France

Corresponding author : Daniel Dudzinski, e-mail : daniel.dudzinski@univ-metz.fr,

phone number : +33387374 286; Fax : +33387315366

\begin{abstract}
In the machining of Inconel 718, nickel based heat resistant superalloy and classified difficultto-cut material, the consumption of cooling lubricant is very important. To reduce the costs of production and to make the processes environmentally safe, the goal is to move toward dry cutting by eliminating cutting fluids. This goal can be achieved by using coated carbide tool and by increasing cutting speed.

The present paper firstly reviews the main works on surface integrity and especially residual stresses when machining Inconel 718 superalloy. It focuses then on the effect of dry machining on surface integrity. Wet and dry turning tests were performed at various cutting speeds, with semi-finishing conditions $(0.5 \mathrm{~mm}$ depth of cut and $0.1 \mathrm{~mm} / \mathrm{rev}$ feed rate) and using a coated carbide tool. For each cutting test, cutting force was measured, machined surface was observed, and residual stress profiles were determined. An optimal cutting speed of $60 \mathrm{~m} / \mathrm{min}$ was determined, and additional measurements and observations were performed. Microhardness increment and the microstructure alteration beneath the machined surface were analysed. It is demonstrated that dry machining with a coated carbide tool leads to potentially acceptable surface quality with residual stresses and microhardness values in the machining affected zone of the same order than those obtained in wet conditions when using the optimised cutting speed value; in addition, no severe microstructure alteration was depicted.
\end{abstract}

Keywords: Inconel 718; Dry machining; Surface integrity; Cutting forces; Roughness; Residual stresses; Microhardness. 


\section{Introduction}

Nickel based superalloys are widely employed in the aerospace industry, in particular in the hot sections of gas turbine engines; this is due to their high temperature strength and high corrosion resistance. They are known as being among the most difficult-to-cut materials. In machining difficult-to-cut materials, the consumption of cooling fluids remains very important. The coolant acquisition, use, disposal and the cleaning of the machined components lead to significant costs, up four times the one of consumable tooling used in cutting operations. The goal for the machining manufacturers is then to move toward dry cutting by eliminating or minimising the cutting fluids use and to improve material removal rate with high speed machining.

In the following, attention is focussed on the Inconel 718 alloy. Due to the low machinability of this material, the worked surface and subsurface are easily affected or damaged during the machining operations. To ensure the better surface integrity, a special care must be taken when choosing cutting conditions, tool material and geometry, and tool coating.

Surface integrity is important for the components submitted to high thermal and mechanical loads during their use (Axinte and Dewes, 2002). Structures in aerospace applications are subjected to severe conditions of stress, temperature and hostile environments. Section size is continually reduced in order to minimise weight; then, surface condition has an everincreasing influence on the performances of the components. Service histories and failure analyses of dynamic components show that severe failures, produced by fatigue, creep and stress corrosion cracking, almost always start or nucleate on or near the surface of components and their origins depend to a great extent on the surface quality. Hence, much attention should be paid to surface characteristics of components, that was pointed first by Field and Khales (1971) and then by Arunachalam et al. (2004) about machining Inconel 718 . Overheating/burning, surface irregularities, Build-Up-Edges or deposits of debris, macro- and microcracks, cavities, microdefects such as laps and inclusions, metallurgical alterations including microstructural distortion, phase transformations, heat affected layers, tensile residual stresses are the main problems identified. Such changes occur due to thermal and mechanical loads during machining. Surface integrity involves surface finish (roughness and waviness), macro- and microstructure and hardness of the surface, microhardness variations, structural changes in the machined surface layer and residual stresses (Field and Khales, 1971). Brinksmeier et al. (1982) gave a good overview of the subject of residual stresses, their measurement and causes in machining processes. Guo and Jawahir, (2009) presented an 
interesting review of the state-of-art on surface integrity characterization and prediction, especially the characteristics of residual stresses in machining of hardened steels and of difficult-to-cut alloys.

Residual stress is one of the most relevant practical parameters used for evaluating the quality of the machined surface, particularly when critical structural components are machined, with the objective to reach the high reliability levels (Outeiro et al., 2008). This is the case for the components made from Inconel alloys, largely used in aerospace industries. Residual stresses are an effect from both heat generated and mechanical work going into the surface and subsurface. More precisely, residual stresses in machining are produced as a consequence of inhomogeneous plastic deformation induced by mechanical and thermal loadings associated with the chip formation process and the interaction between the tool and the freshly machined surface in the vicinity of the tool nose (Ezugwu et al., 1999). Thermal effects tend to give tensile stresses, while mechanical influences contribute to compressive residual stresses (Axinte and Dewes, 2002). Phase transformations can support the development of both compressive and tensile residual stresses depending on the relative volume changes and the accompanying plastic deformations (Ezugwu et al., 1999). Residual stresses strongly affect the fatigue life of a component. The introduction of a compressive mean stress will increase the allowed alternating stress for a given fatigue life and then is generally beneficial. Conversely, a tensile mean stress reduces the allowed alternating stress in service. In consequence, high tensile stresses generated by the machining of work hardening alloys may be highly deleterious to fatigue performance. The effect is most significant in the high cycle fatigue regime where the applied stress magnitude is not sufficient to significantly relax the residual stresses produced during manufacturing.

Near surface residual stress distributions in Inconel 718 arising from a turning operation were studied by Schlauer et al. (2002). The cutting conditions were very similar to orthogonal cutting. The cutting tool used was a $\mathrm{SiC}$ whisker-reinforced alumina $\mathrm{Al}_{2} \mathrm{O}_{3}$ ceramic. Cutting speeds were 10,410 and $810 \mathrm{~m} / \mathrm{min}$ and for the feed were $0.01,0.06$ and $0.11 \mathrm{~mm} / \mathrm{rev}$. For the cutting speed of $10 \mathrm{~m} / \mathrm{min}$, low compressive residual stresses were found. At higher cutting speeds of 410 and $810 \mathrm{~m} / \mathrm{min}$, a thin layer exhibiting tensile residual stresses was formed near the machined surface, with a maximum tensile stress at the surface. This layer was followed by a zone with compressive stresses that is several times thicker than the tensile 
layer. When the cutting speed attained its higher value, the two zones were enlarged and the maximum values of the tensile and the compressive stresses were increased.

Similar stress profiles were found by Derrien and Vigneau (1997) and Guerville and Vigneau (2002). They carried out high speed and dry milling tests (contouring and point milling) with uncoated cemented carbide K20 mills. For contouring operations at $V=200 \mathrm{~m} / \mathrm{min}, f=0.04$ $\mathrm{mm} /$ tooth and a depth of cut of $0.5 \mathrm{~mm}$, residual stresses are tensile, affecting a layer of 400 $\mu \mathrm{m}$ with an extreme value of $1500 \mathrm{MPa}$. This maximum value was three times the one obtained using a more conventional speed of $16 \mathrm{~m} / \mathrm{min}$ and wet conditions. On the other hand, for the point milling tests, the level of the residual stresses was lower with a maximum tensile stress value of about $750 \mathrm{MPa}$ near the machined surface, a maximum compressive stress value of $500 \mathrm{MPa}$ and a $100 \mu \mathrm{m}$ affected layer.

Comparable residual stress profiles were also obtained after ball end milling by $\mathrm{Ng}$ et al. (2002). The tests were performed at a cutting speed of $90 \mathrm{~m} / \mathrm{min}$, a feed of $0.2 \mathrm{~mm} /$ tooth and an axial depth of cut of $0.5 \mathrm{~mm}$ in down milling; the workpiece surface was inclined with an angle of $45^{\circ}$ from the horizontal. High tensile stress values were measured parallel to the feed direction near the machined surface, followed by highly compressive stress at a shallow depth and the compressive layer was maintained to $150 \mu \mathrm{m}$.

Arunachalam et al. (2004) studied residual stresses and surface finish when facing age hardened Inconel 718 using two grades of coated carbide cutting tools. The cutting speed, feed, and depth of cut were maintained constant at $60 \mathrm{~m} / \mathrm{min}, 0.10 \mathrm{~mm} / \mathrm{rev}$ and $0.5 \mathrm{~mm}$, respectively. Only the effect of cutting tool parameters (insert shape, cutting edge preparation, negative or positive rake angle, nose radius, and effect of coolant) was examined. They concluded that these parameters have a significant role in determining residual stresses profile, and suggested that coated carbide cutting inserts of round shape, chamfered cutting edge, negative rake type and small radius $(0.8 \mathrm{~mm})$ and coolant generate small values of residual stresses, which are mostly compressive.

Sharman et al. (2006) carried out a series of turning Inconel 718 experiments. Using coated and uncoated WC tools, they evaluated the effects geometry, wear level and operating parameters (the tested cutting speed, and feed rate were 40,80, $120 \mathrm{~m} / \mathrm{min}$ and $0.15,0.25$ $\mathrm{mm} / \mathrm{rev}$ ) on surface integrity. When cutting with a new tool relatively little plastic deformation of the grains boundaries occurred and all the samples were strain hardened in the 
near surface layer. The residual stress profile was tensile near the surface layer before rapidly dropping to compressive values; the depth of the affected layer was $200 \mu \mathrm{m}$. When cutting using the same operating conditions, the surface produced with the coated tool had higher tensile stress (up to $747 \mathrm{MPa}$ ) than the corresponding surface cut with the uncoated tool. This increase of tensile stress is due to the fact that the coated tool has a multilayer coated containing a thermal barrier of $\mathrm{Al}_{2} \mathrm{O}_{3}$; that leads to an increase of workpiece surface temperature to a higher level causing higher tensile residual stresses. When the cutting speed was increased, the peak tensile stress reduced and the greatest reduction was obtained between 40 and $80 \mathrm{~m} / \mathrm{min}$. The increase of feed rate resulted to an increased stress levels. The same authors performed, in a next study, Sharman et al. (2008), a series of experiments examining the effects of varying cutting fluid supply pressure when finish turning Inconel 718. The cooling fluid was supplied to the rake face, or to the flank face, or to rake and flank faces simultaneously at various pressures. Surprisingly, no increase in tool life was observed when using a high pressure, up to 450 bar. In addition, cutting fluid supply pressure and direction of the jet had relatively little influence on the level of surface integrity. More precisely, in comparison with conventional flood cooling (5 bar), cutting with 450 bar supplied to the rake face increased the tensile stress in the near-surface layer. Nevertheless it must be noted that a significant reduction in the level of this tensile stress was observed when the 450 bar coolant was directed at the flank face. That suggests that, in this case, lower workpiece temperatures were developed.

To obtain the optimum machining conditions that give high integrity for high speed turned Inconel 718 machined surfaces, Pawade et al. (2008) proposed criteria based on residual stress analysis, microhardness measurements and work hardening evaluation in the machined subsurfaces. Using a statistical analysis of their results, they observed that the highest cutting speed $(475 \mathrm{~m} / \mathrm{min})$, the lowest feedrate $(0.05 \mathrm{~mm} / \mathrm{rev})$, and the moderate depth of cut $(0.5$ $0.75 \mathrm{~mm}$ ) coupled with the use a PCBN insert with a honed cutting edge and a negative rake angle can produce compressive residual stresses at the surface of the machined workpiece. In addition, with the founded optimal conditions the machined surfaces were free of smeared areas and adhered chip particles.

As it was reported previously, the main works concerning machining Inconel 718 were performed using a cutting fluid; and thus the effect of dry conditions was little investigated. In the following, results about surface integrity (surface finish and residual stresses) during 
turning of Inconel 718 are presented and the role played by the suppression of cutting fluid is analysed. The machining tests were performed using a coated cemented carbide tool, under dry and wet conditions. Different values of cutting speed were chosen.

For the measurement of residual stresses, the X-Ray diffraction method was used. Surface quality was investigated using white light interferometry microscopy and the cutting forces were determined from feed motor and spindle powers consumptions and directly using a dynamometer table. Additional measurements and observations were performed to complete the surface integrity analysis in dry conditions in comparison with the one in wet conditions. Microhardness measurements were carried out at various locations on the cross section of the machined samples to determine the machining affected layer by plastic deformation, and subsurface was observed using scanning electron microscope to evaluate the microstructure alteration.

\section{Experimental procedure}

The workpiece material used was the Inconel 718 alloy with a chemical composition of 52.5\% $\mathrm{Ni}, 19 \% \mathrm{Cr}, 18.5 \% \mathrm{Fe}, 5.1 \% \mathrm{Nb}, 3 \% \mathrm{Mo}, 0.9 \% \mathrm{Ti}, 0.5 \% \mathrm{Al}, 0.04 \% \mathrm{C}, 0.2 \% \mathrm{Si}, 0.2 \% \mathrm{Mn}$ (weight percent). This material was solution treated and aged to a nominal bulk hardness of 44 HRC. The microstructure of the Inconel 718 alloy is shown in Fig. 1, inhomogeneous grain size structure may be observed. This work material was supplied in bar form of $180 \mathrm{~mm}$ diameter.

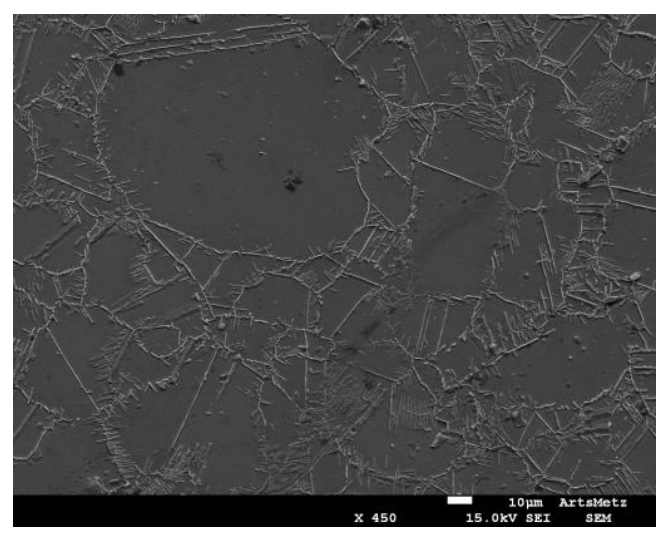

Fig. 1 Microstructure of the Inconel 718 alloy.

All the bar turning tests were conducted on a CNC lathe RAMO RTN 30 employing a spindle with a maximum speed of $3800 \mathrm{rev} / \mathrm{min}$ and drive motor rated up to $38 \mathrm{~kW}$. Dry and wet machining experiments were performed with different cutting speeds referenced in table 1 . 
The cutting fluid was a 5\% emulsion supplied using the CNC lathe coolant system at 5 bar / $25 \mathrm{l} / \mathrm{min}$.

\begin{tabular}{ccccc}
\hline $\begin{array}{c}\text { Sample } \\
\text { number }\end{array}$ & $\begin{array}{c}\text { Cutting speed } \\
V_{c}(\mathrm{~m} / \mathrm{min})\end{array}$ & $\begin{array}{c}\text { Feed rate } f \\
(\mathrm{~mm} / \mathrm{rev})\end{array}$ & $\begin{array}{c}\text { Depth of cut } a_{p} \\
(\mathrm{~mm})\end{array}$ & $\begin{array}{c}\text { lubrication } \\
\text { Wet or dry }\end{array}$ \\
\hline S1 & 80 & 0.1 & 0.5 & dry \\
S2 & 60 & 0.1 & 0.5 & dry \\
S3 & 40 & 0.1 & 0.5 & dry \\
S4 & 80 & 0.1 & 0.5 & wet \\
S5 & 60 & 0.1 & 0.5 & wet \\
S6 & 40 & 0.1 & 0.5 & wet \\
\hline
\end{tabular}

Table 1 - Cutting conditions used for the samples.

Tests were carried out to investigate the effect of cutting speed and of cutting fluid use or of dry conditions. Machining parameters fixed throughout these trials were depth of cut $(0.5$ $\mathrm{mm})$ and feed rate $(0.1 \mathrm{~mm} / \mathrm{rev})$, corresponding to semi-finishing conditions.

The cutting tools were coated inserts S05F supplied by Sandvik-Coromant without chip breaker. The $\mathrm{S} 05 \mathrm{~F}$ insert grade is a CVD TiCN $-\mathrm{Al}_{2} \mathrm{O}_{3}-\mathrm{TiN}$ coated grade of $4 \mu \mathrm{m}$ thickness, with high hot hardness and good coating adhesion, and with fine grain substrate. The tool radius was $0.4 \mathrm{~mm}$, the rake and the clearance angles were respectively $0^{\circ}$ and $7^{\circ}$. The used tool holder was a PTGNR $2020 \mathrm{~K} 16$ with an approach angle $K_{r}$ of $90^{\circ}$.

Cutting forces were measured with a WattPilote ${ }^{\circledR}$ Turning System (Devillez et al. 2007; digitalway 2009) usually used to prevent excessive tool wear and tool breakage on machine tool. In the same way, the currents of the spindle and feed motors were used by Li and Tso (1999) to estimate tool wear state during drilling, and by Jeong and Cho (2002) to determine cutting forces during milling operations. For each cutting test, the power consumed by the spindle was measured and converted into cutting forces. To verify the obtained values, the cutting forces were also measured, for some cutting conditions, with a three-component piezoelectric dynamometer Kistler 9265 B table associated to a 5017 multichannel charge amplifier connected to a DEWE-2010 Dewetron data acquisition system.

After machining, sections from workpiece were taken to examine the machined surface, to measure the surface roughness and to evaluate the microhardness. Microhardness measurements were conducted using a Vickers indenter Zwick ZHV1 at a load of $100 \mathrm{~g}$ for 10s; series of measurements were taken and an average obtained. Subsurface microstructural analysis was conducted with a Jeol SEM, scanning electron microscope. After polishing 
operation, grain boundaries were revealed with an electrolytic etch of $\mathrm{HCl}$ solution under a $6 \mathrm{~V}$ dc current during $5 \mathrm{~s}$.

The machined surface observations and measurements were performed with a Veeco NT 1100 (Wyko®) optical profiler, using the white light interferometry technique with a resolution of $2 \mathrm{~nm}$ on the optical Z-axis (Devillez et al. 2007). The same technique was used to examine the tool wear patterns.

Additional specimens were removed from the bar using wire electro-discharge machining to residual stress evaluation. Residual stresses measurements were made using the X-ray stress analysis technique with a Fe-anticathode and a manganese filter. They were measured in both feed and cutting directions, determined according the $\sin ^{2} \psi$-method. To obtain information about the stress state in deeper layers, surface layers were repeatedly removed by electropolishing in an electrolyte of phosphoric and sulphuric acid.

\section{Results and discussion}

\subsection{Cutting forces, surface roughness}

The effect of lubrication and cutting speed on cutting forces and surface roughness was first studied; the experimental results are shown respectively on Figure 2 and Figure 3. The cutting forces were calculated from the spindle power and the feed motor power consumption measurements. The cutting force, Figure 2, initially decreases with increasing cutting speed and presents a minimum value for the cutting speed of $60 \mathrm{~m} / \mathrm{min}$. Dry conditions provide always lower cutting force values. When cutting speed increases, from 40 to $60 \mathrm{~m} / \mathrm{min}$, or when dry cutting is chosen, higher temperatures are surely generated in the primary shear zone. These higher temperatures lead to a decreasing of workpiece mechanical properties (thermal softening) and thus to a decrease of cutting forces. Over $60 \mathrm{~m} / \mathrm{min}$, the observed increase of cutting force is believed to be due to strain rate sensitivity which becomes, in its turn predominant over thermal softening. It is well known that Inconel 718 is very strain rate sensitive, Ezugwu et al. (1999), Dudzinski et al. (2004). In consequence, the obtained cutting force evolution with cutting speed is the result of the competition between these two material characteristics.

For surface roughness Ra, a comparison between dry and wet conditions is presented Figure 3. In dry conditions, surface roughness Ra has a tendency to decrease with increase in cutting 
speed. In wet conditions, surface roughness decreases with higher cutting speed values only after the value of $60 \mathrm{~m} / \mathrm{min}$. The cutting speed value of $60 \mathrm{~m} / \mathrm{min}$ appears to be the optimal one, it minimises cutting force and improves the surface finish Ra in dry conditions.

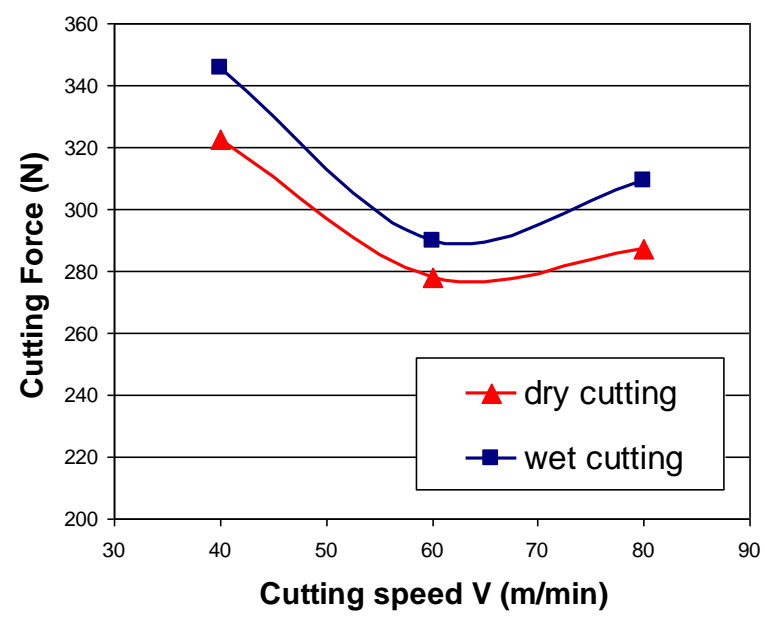

Fig. 2 - Effect of cutting speed and, lubrication on cutting forces.

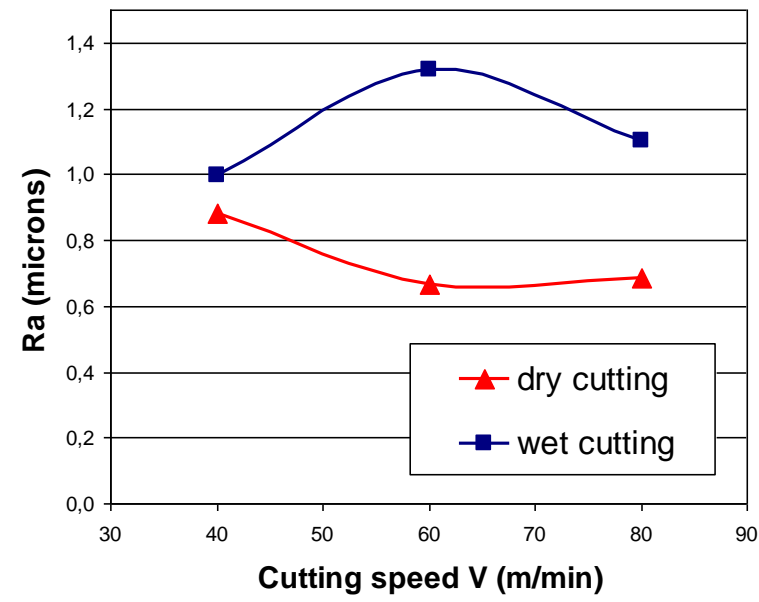

Fig. 3 - Effect of cutting speed and lubrication on surface finish.

\subsection{Surface quality}

Figures 4 present 3D images of the machined surfaces at the various cutting conditions given on table 1. Surface irregularities may be observed between the feed marks on dry cutting specimens (Figures $4 \mathrm{a}, \mathrm{b}, \mathrm{c}$ ). These irregularities may correspond to residual worked material deposition on the machined surfaces, this worked material coming from the tool faces. During dry machining of Inconel 718, worked material adheres to the tool faces (rake and flank tool faces) to form Built-Up Layer (BUL) and Built-up Edge (BUE), see Figures 5. According to the high temperature and the high pressure taking place at the tool tip, this BUE is deformed plastically and flows in the chip flow direction. Fragments of work material deposition on tool 
faces are regularly evacuated by chips and by the new machined surface. Similar effects were reported by other authors during dry machining Inconel 718 with coated carbide, see for example Arunachalam et al . (2004) or Pawade et al. (2007).

In the case of wet cutting, tool surfaces are cooler than in dry cutting that prevents or reduces the adhesion tool wear. The deposition of residual built up edge to the machined surface is then reduced or cancelled (Figures $4 \mathrm{~d}$ and e), and as a consequence the machined surface quality is better in wet conditions.

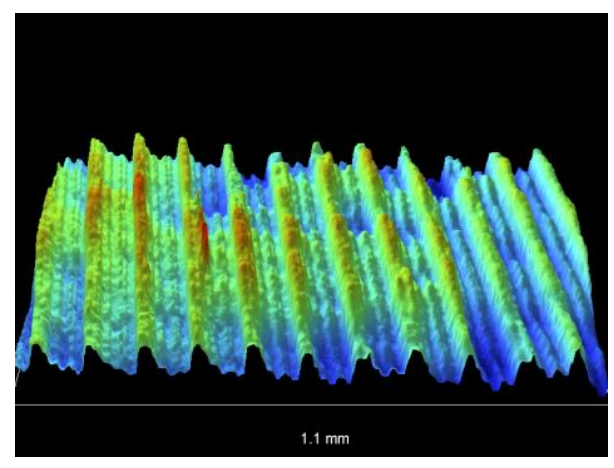

(a) $V=80 \mathrm{~m} / \mathrm{min}$, dry conditions

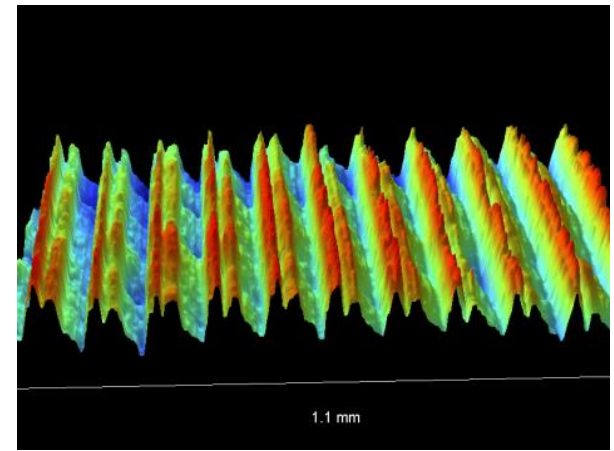

( b ) $V=60 \mathrm{~m} / \mathrm{min}$, dry conditions

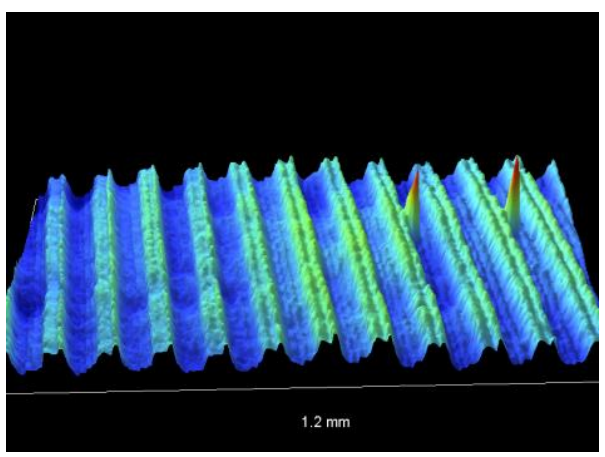

(c) $V=40 \mathrm{~m} / \mathrm{min}$, dry conditions

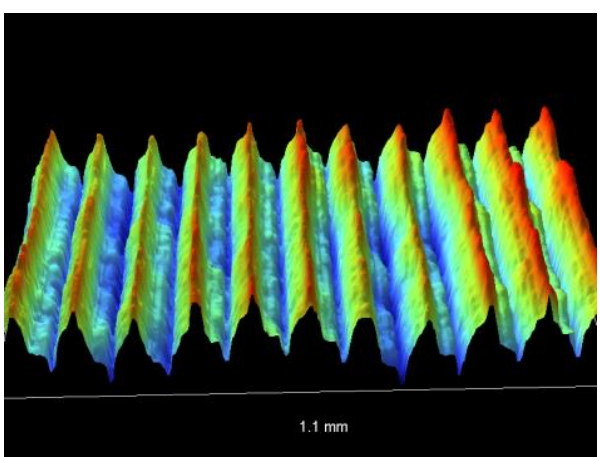

(d) $V=80 \mathrm{~m} / \mathrm{min}$, wet conditions

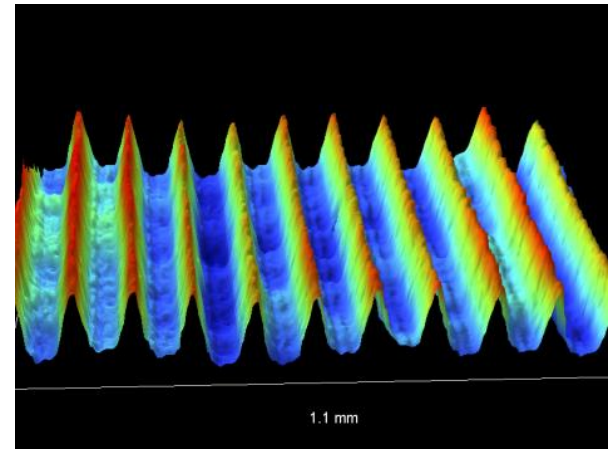

(e) $V=60 \mathrm{~m} / \mathrm{min}$, wet conditions

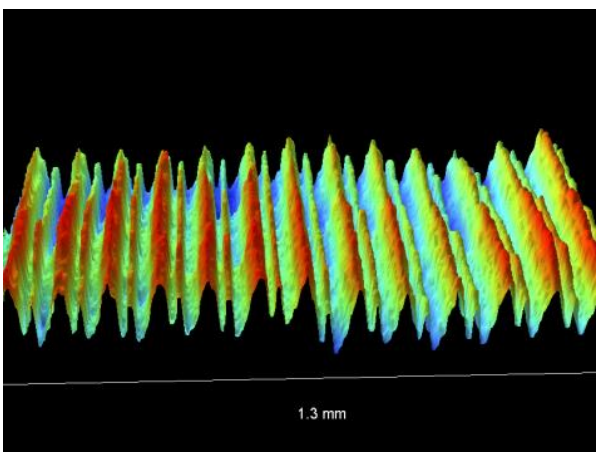

$(f): V=40 \mathrm{~m} / \mathrm{min}$, wet conditions

Fig. 4 - Surface quality observations, for various cutting conditions, using the white light interferometry technique. 
Material side flow is also observed along the feed marks and also in between the feed marks. This mechanism of material side flow during turning was analysed and explained by Kishawy and Elbestawi (1999). When the chip thickness is lower than a minimum value, workpiece material is ploughed, squeezed and deformed plastically by the tool nose. Material side flow is facilitated by tool trailing edge wear where material plastic flow fills the groove to leave these double marks (Figures $4 \mathrm{~b}, \mathrm{c}, \mathrm{f}$ ).

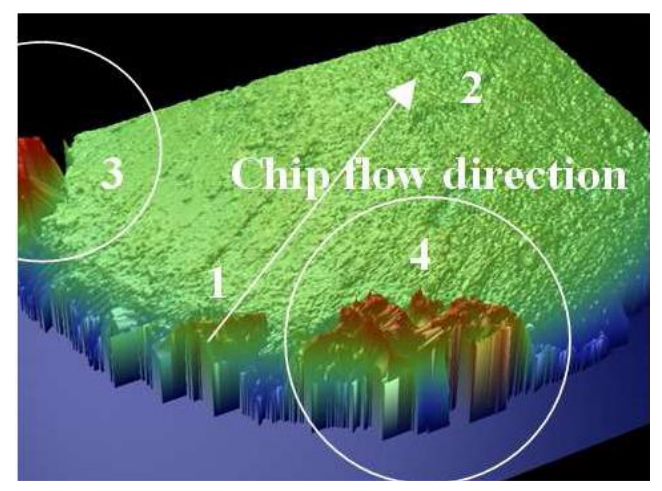

(a)

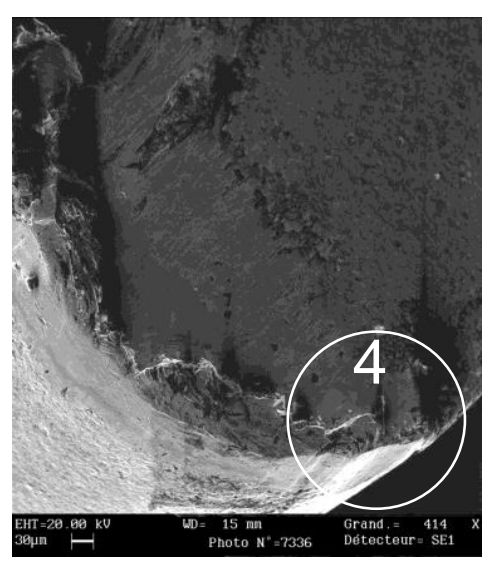

(b)

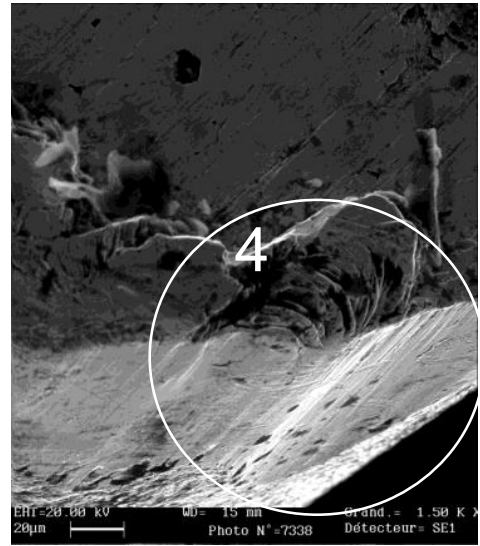

(c)

Fig. 5 - tool wear patterns when turning Inconel 718 obtained by using (a) white light interferometry microscope and (b) and (c) SEM observations .

Figure 5 gives typical views of the tool faces after machining Inconel 718, with a feed rate of $0.1 \mathrm{~mm} / \mathrm{rev}$. BUE is depicted on the tool rake face; notch wear is observed at the depth of cut (zone 3, Figure 5a). For the cutting speed values used in this study the chips were serrated, and the serrated edge of the chip abrades the tool leading to produce notch wear at the depth of cut with material accumulation. At the other end, at the trailing edge of the tool, where the chip thickness is a minimum, workpiece material accumulation is also observed (zone 4, Figure 5a). In flank face, in addition to the characteristic wear land formed from the rubbing action of the newly generated workpiece surface, a small notch covered by workpiece material is depicted, Figure $5 \mathrm{~b}$ and $\mathrm{c}$. 
The tool wear patterns observation confirms the previous propositions. First, due to the BUE formation, fragments of work material were broken away and evacuated by the new generated surface. These fragments covered the machined surface and contributed to the machined surface roughness and quality. In dry conditions, they led to a more rough surface aspect and a lower Ra value, figures 4 a, b and c. Secondly, following the hypothesis of Kishawy and Elbestawi (1999), facilitated by trailing edge wear, material side flow took place to generate double marks and plastic flow at the feed marks, Figures 4a,b,c and f.

Finally, the better surface quality was obtained in wet conditions at the cutting speed of $60 \mathrm{~m} / \mathrm{min}$, but with the higher roughness $\mathrm{Ra}$ value. The lower roughness $\mathrm{Ra}$ value was obtained at the same cutting speed but in dry conditions.

\subsection{Tool life in dry conditions}

Additional machining tests were performed to verify if the tool life attains acceptable values, in dry conditions. In accordance with ISO 3685-1977 (E), the tool wear criterion used was when the maximum width of the flank wear land was equal or greater than $\mathrm{Vb}_{\max }$ of $0.2 \mathrm{~mm}$, or when it appeared a catastrophic failure. It can be observed, on figure 6, that tool life decreases with increasing cutting speed. However, in terms of length of cut, the cutting speed values of 40 and $60 \mathrm{~m} / \mathrm{min}$ exhibited the same tool life. Kamata and Obikawa (2007) obtained comparable results with a CVD TiCN/Al ${ }_{2} \mathrm{O}_{3} / \mathrm{TiN}$ coated tool when dry machining Inconel 718 , but for a finish-turning operation (depth of cut of $0.1 \mathrm{~mm}$ and feed of $0.1 \mathrm{~mm} / \mathrm{rev}$ ) at a cutting speed of $60 \mathrm{~m} / \mathrm{min}$. In addition, they have shown that dry cutting is preferable to wet cutting, in terms of surface roughness Ra, and that it does not drastically decrease tool life. In the same way, Ducros and al. (2003) obtained a tool life of $7 \mathrm{~min} 30$ s with a nanolayer TiN/AlTiN coated tool used for turning Inconel 718 with a depth of cut of $1.5 \mathrm{~mm}$ at a cutting speed $V_{\mathrm{c}}=40 \mathrm{~m} / \mathrm{min}$, and a feed $f=0.2 \mathrm{~mm}$, in wet conditions. 


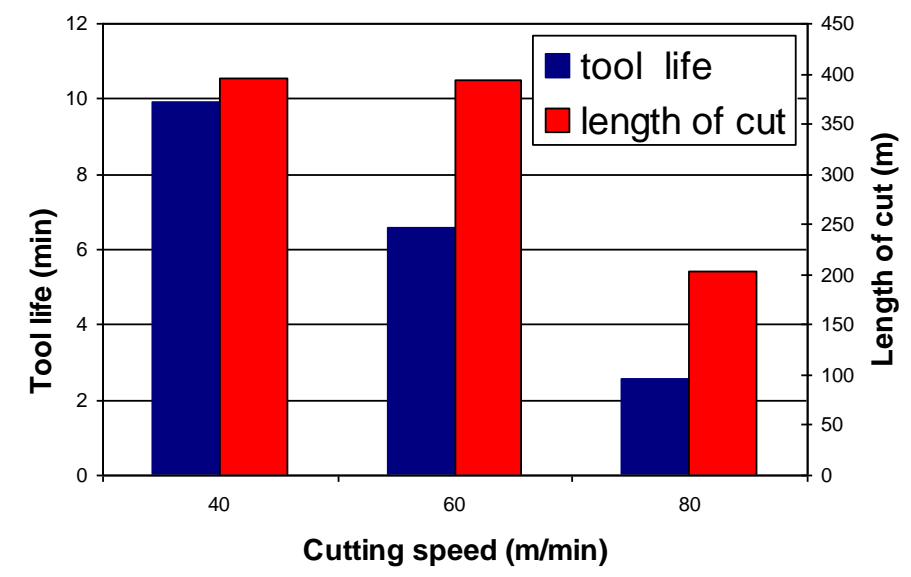

Fig. 6- Effect of cutting speed on tool life for dry turning Inconel.

\subsection{Residual stresses}

Gunnberg et al. (2006) remind in their paper, the residual stress mechanisms. The thermal residual stress mechanism is due to the heat of the cutting process, which expands the surface layer and produces firstly compressive stress. The workpiece is then cooled and contractions in the surface layer produce tension residual stress. The thermal effect decreases further inside the workpiece, thus the main consequence of tension stress is on the newly machined surface. Consequently, the temperature of the cutting edge is very important for reducing tensile residual stress. The mechanical residual stress during cutting can be explained by a plastic deformation in the surface layer and elastic deformation in the underlying surface layer. To achieve force equilibrium and geometric compatibility after the cutting process, elastic rebalancing places the surface layer in residual compressive stress.

As mentioned in previous cited papers, Inconel 718 has high mechanical properties and exhibits severe work hardening, combined with low thermal conductivity. As a consequence, high cutting forces are produced with high localized temperatures around the cutting edge, and on the machined surface, thus producing high tensile residual stress levels, figure 7 . Depending on cutting speed value and on lubrication, this tensile residual stress may reach $1000 \mathrm{MPa}$ in cutting direction. 

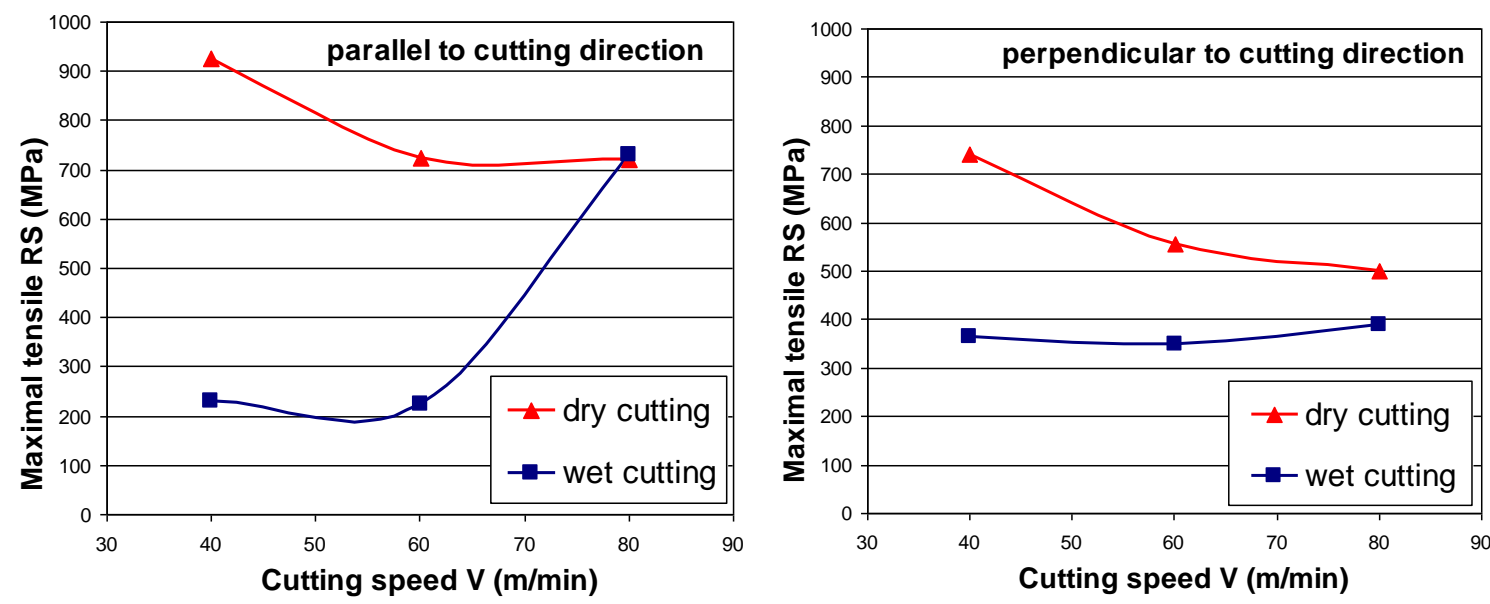

Fig.7 - Tensile residual stresses at the machined surface.

It can be also noted that, in dry conditions, when cutting speed was increased the peak tensile stress reduced, Figure 7, and then it may be supposed that the heat generation reduced too. This drop in surface tensile residual stress can be explained by the increase of chip flow rate associated with increasing cutting speed. A higher chip flow rate limits the length of time available for the heat generated in the primary shear zone to diffuse into the workpiece surface and consequently increases the amount of thermal energy evacuated by the chip (Sharman et al., 2006).

In-depth residual stress profiles in cutting and feed directions, induced in dry and wet turning of Inconel 718, were measured, Figure 8. For the range of cutting conditions investigated, the residual stress profile is tensile at the surface with values depending on cutting conditions (wet or dry conditions and cutting speed value). With increasing depth beneath the machined surface, the tensile stress shifts to compressive values before stabilizing at the level corresponding to that found in the work material before machining, around zero MPa.

When comparing residual stresses in dry and wet conditions, it appears that tensile stress is reduced by the use of a lubricant. The cutting fluid limits the temperature attained on the new generated surface and then reduces this tensile stress. The compressive stresses are not greatly modified by lubrication. The thickness of the under-layer affected by residual stresses, Figure 9, presents the same profile in dry and wet conditions, with a minimum for the cutting speed of $60 \mathrm{~m} / \mathrm{min}$.

The effect of lubrication on residual stresses is nevertheless limited at high cutting speeds, and for the higher cutting speed of $80 \mathrm{~m} / \mathrm{min}$. For this cutting speed, the profiles and levels of 
residual stresses are very similar in wet and dry conditions. That may be explained by the fact that at high cutting speeds, the cooling effect of lubrication is not so efficient.
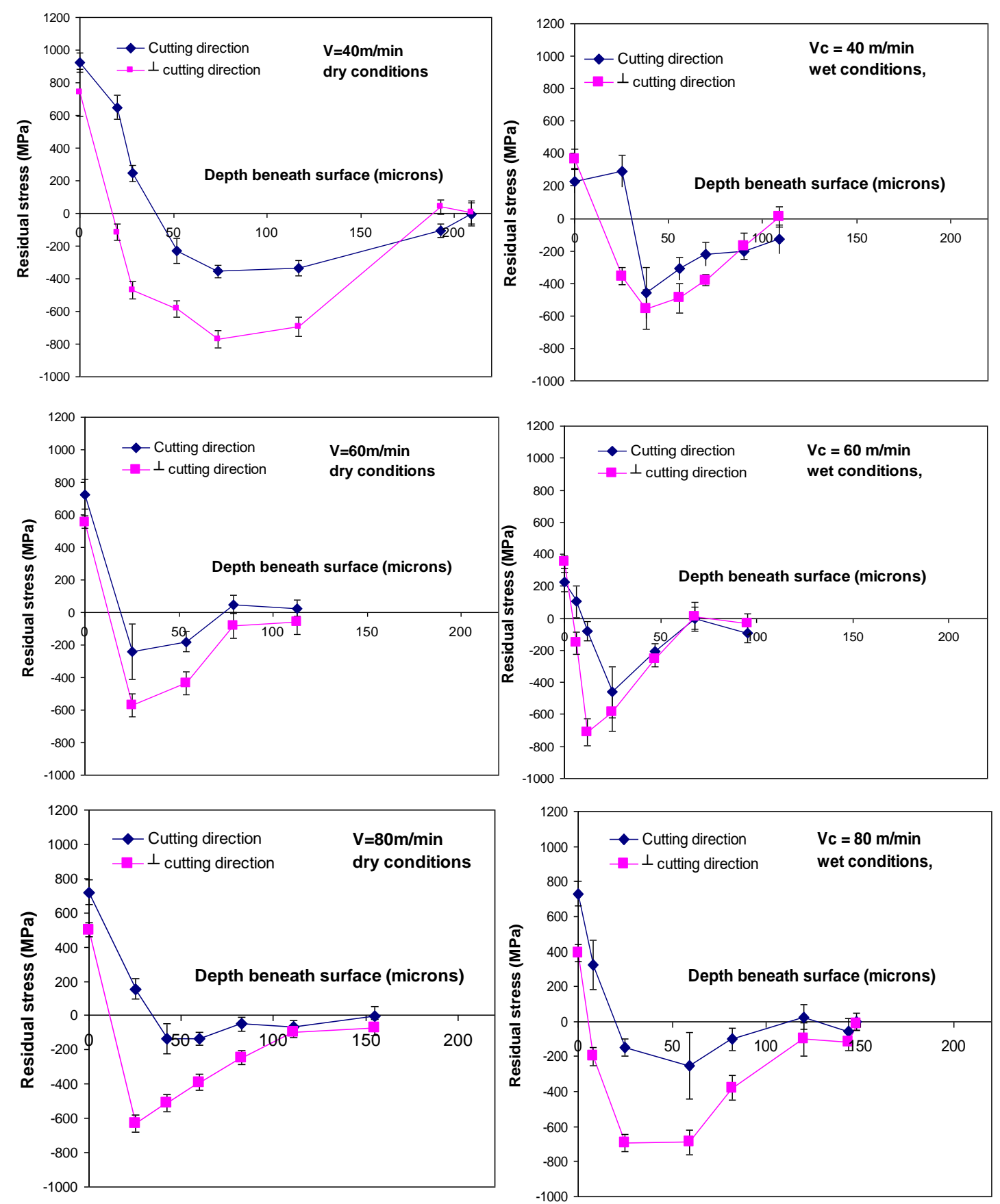

Fig. 8 - Residual stresses generated by the machining. 


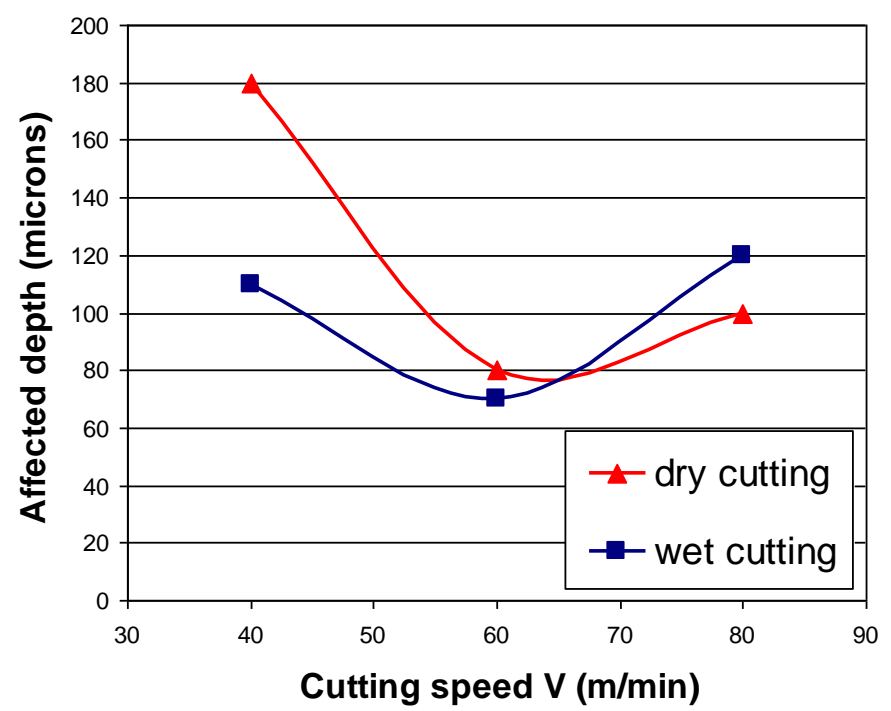

Fig. 9- Affected depth by residual stresses after machining.

\subsection{Micro-hardness profile and subsurface microstructure}

When examining cutting forces, Figure 2, surface finish quality Ra, Figure 3, and residual stresses, Figure 8, and affected depths, Figure 9, it appears that the cutting speed of $60 \mathrm{~m} / \mathrm{min}$ in dry cutting (sample 2) gives globally the better results. For these conditions, the cutting force is limited to $275 \mathrm{~N}$, the surface finish Ra has a low value of $0.65 \mu \mathrm{m}$, the affected depth by residual stresses is reduced to $80 \mu \mathrm{m}$ and the tensile stress attains relatively acceptable values. The comparison of these results with those obtained for the lower cutting speed of $40 \mathrm{~m} / \mathrm{min}$ and for the higher speed of $80 \mathrm{~min}$, leads to state that dry cutting at $60 \mathrm{~m} / \mathrm{min}$ may be considered as optimal.

Additional observations and measurements were performed with the samples corresponding to the cutting speed of $60 \mathrm{~m} / \mathrm{min}$. Wet and dry subsurface microstructures in the direction of cutting were studied and compared, Figure 10. The observed microstructures reveal the inhomogeneous grain size structure. Also, relatively little plastic deformation of the grain boundaries occurred near the machined surface, in wet conditions; and no significant damage or defects are visible in wet and dry conditions. In dry conditions, it seems that in a small layer, 10-20 $\mu \mathrm{m}$ beneath the machined surface, an elongation of the grain structures and a directional orientation of the grain boundaries are visible and more significant than in wet conditions; however, this deformation remains relatively moderate in comparison with the microstructural deformation observed by Sharman et al. (Sharman et al., 2008) after machining Inconel 718 with a worn tool. In their study, they have shown the limited incidence of the coolant pressure on the microstructure deformation. Finally, Figure 10 reveals also that, 
compared with wet conditions, dry conditions have a low incidence on the microstructure deformation and damage.

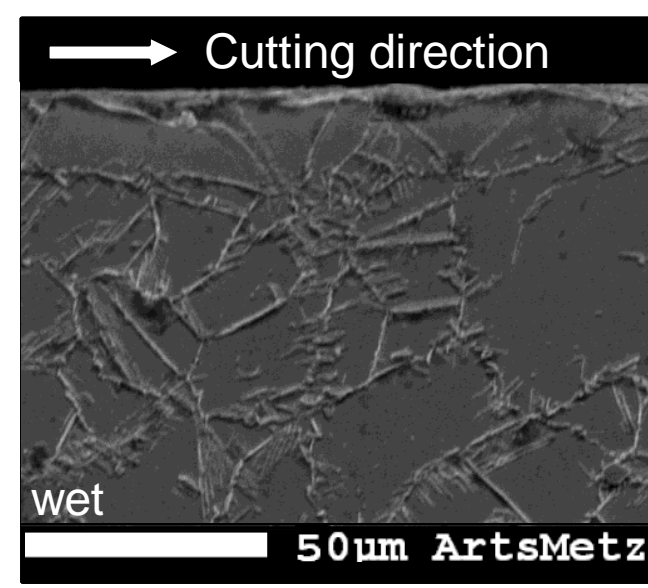

(a)

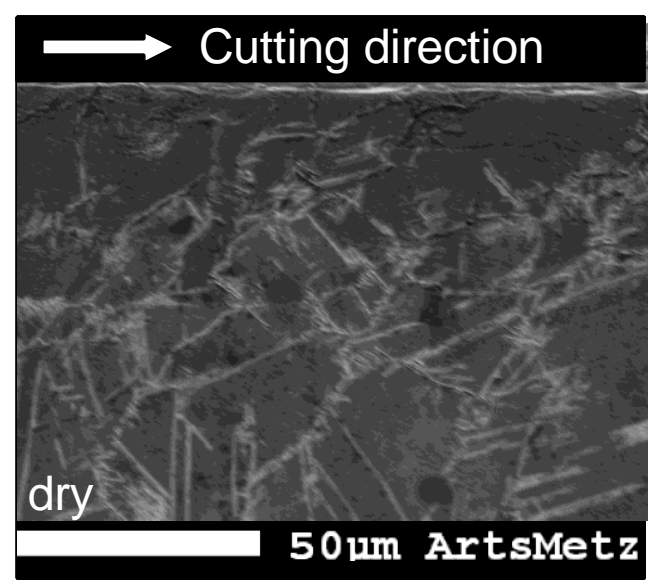

(b)

Fig. 10 - Subsurface microstructure after (a) wet and (b) dry cutting at a speed of $60 \mathrm{~m} / \mathrm{min}$

Measurements of microhardness were carried out at various locations on the cross section of the machined samples in dry and wet conditions at cutting speed of $60 \mathrm{~m} / \mathrm{in}$. for these two conditions, a gradient is observed in the subsurface, Figure 11. The workpiece was hardened at the surface $\left(525 \mathrm{HV}_{0.1}\right.$ and $510 \mathrm{HV}_{0.1}$ for dry and wet conditions, respectively) with a gradual return to bulk values $\left(430-440 \mathrm{HV}_{0.1}\right)$ at about $250 \mu \mathrm{m}$ beneath the machined surface. Comparable microhardness values and gradients were measured by Pawade et al. (2008) and by Ezugwu and Tang (1995); these measurements confirm the plastic deformation of the surface layer after machining Inconel 718.

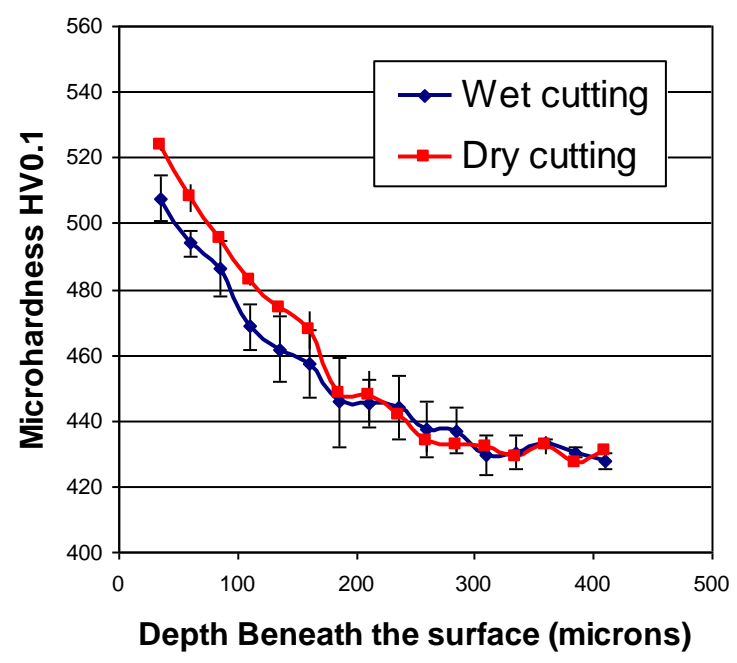

Fig. 11 - Effect of cutting condition on microhardness at a speed of $60 \mathrm{~m} / \mathrm{min}$. 


\section{Conclusions}

This paper presents results in terms of surface integrity and cutting forces, when turning Inconel 718, in wet and dry conditions. The study combines different techniques to characterise cutting performance and surface integrity. Cutting forces were measured by power consumed recorder. Roughness, analyse of the machined surface and tool wear modes were observed with white light interferometric microscopy technique and residual stresses were determined using an X-ray stress analysis technique. Additional data about microstructure were obtained using FEM technique and micro hardness tests. Dry and wet machining conditions were compared for three different cutting speeds.

1. Even the cutting forces levels are very similar in wet and dry conditions; they are nevertheless systematically reduced in dry conditions. In addition, the surface roughness $\mathrm{Ra}$ is largely decreased.

2. In dry conditions, the surface quality is altered by the deposition of residual built up edge to the machined surface; this is due to the higher temperatures generated.

3. In dry and in wet conditions, material side flow is observed in the area of the feed marks.

4. All residual stresses profiles present a thin layer exhibiting tensile residual stresses near the machined surface, with a maximum tensile stress at the surface. This layer is followed by a zone with compressive stresses, several times thicker than the tensile layer.

5. High tensile residual stresses are produced. This is due to the high mechanical properties of Inconel 718, combined with its low thermal conductivity, which leads to high temperature around the cutting edge.

6. When comparing residual stresses in dry and wet conditions, it appears that tensile stress is limited by the use of a lubricant. However, this effect of lubrication is reduced when increasing the cutting speed, leading to equivalent tensile stress values for a cutting speed of $80 \mathrm{~m} / \mathrm{min}$.

7. In dry conditions, when cutting speed was increased the peak tensile stress was reduced. At high cutting speed, the heat generated during chip formation is mostly evacuated by the chip. 
8. For the used coated tool, it appears that, in dry conditions, the cutting speed of 60 $\mathrm{m} / \mathrm{min}$ may be considered as optimal. This cutting condition globally optimises surface finish quality Ra, limits residual stresses and affected depths and tensile stress. For the selected cutting speed condition, the suppression of the lubricant has a low influence on the microstructure deformation and the microhardness gradient in the machined surface layer, in comparison with wet machining.

\section{Acknowledgements}

The research work published in this paper was carried out with the financial aid of ADEME, French Agency for Environment and Energy Management and we would to thank their members for their help and their support during the project.

Gratefully acknowledgements for Dr. S. Berveiller and Dr. R. Pesci from Arts\&Métiers Metz, for their help on the determination of residual stresses on the samples and for the SEM observations. 


\section{References}

Axinte, D.A. and R.C Dewes, 2002. Surface integrity of hot work tool steel after high speed milling experimental data and empirical models. Journal of Materials Processing Technology. $127,325-335$.

Arunachalam, R.M., M.A. Mannan, and A.C. Spowage, 2004. Surface integrity when machining age hardened Inconel 718 with coated cutting tools. International Journal of Machine tools and Manufacture. 44, 1481-1491.

Brinkmeier, E., J.T. Cammet, W. König, P. Leskovar, J. Peters, J. and K. Tönshoff, 1982. Residual stresses, measurement and causes in machining processes. Annals of the CIRP. 31, 2, 491-510.

Ducros, C., Benevent, V., Sanchette, F., 2003. Deposition characterization and machiing performance of multilayer PVD coatings on cemented carbide cutting tools. Surface and coatings Technology. 163-164, 681-688.

Devillez, A., F. Schneider, S. Dominiak, D. Dudzinski, and D. Larrouquere, 2007. Cutting forces and wear in dry machining of Inconel 718 with coated carbide tools. Wear. 262, 931942.

Dudzinski, D., Devillez, A., Moufki, A. Zerrouki, V., Larrouquere, D., Vigneau, J., 2004, A Review of Developments Towards Dry and High Speed Machining of Inconel 718 Alloy, International Journal of Machine Tools and Manufacture,44,Issue 4, 439-456.

Derrien, S., and J. Vigneau, 1997. High speed milling of difficult to machine alloys. Proceedings of the 1st French and German Conference on High Speed Machining, edited by A. Molinari, H. Schulz and H. Schulz, University of Metz-France.

Ezugwu, E.O., Z.M. Wang, A.R. Machado, 1999. The machinability of nickel-based alloys: a review. Journal of Materials Processing Technology. 86, 1-16.

Ezugwu, E.O., and S.H. Tang, 1995. Surface abuse when machining cast iron (G-17) and nickel base superalloy (Inconel 718) with ceramic tools, Journal of Materials Processing Technology, 55, 63-69

Field, M. and J.F. Khales, 1971. Review of surface integrity of machined components. Annals of CIRP. 20, 2, 153-163.

Gunnberg, F., M. Escursell, and M. Jacobson, 2006. The influence of cutting parameters on residual stresses and surface topography during hard turning of $18 \mathrm{MnCr} 5$ case carburised steel. Journal of Materials Processing Technology. 174, 82-90.

Guo Y.B., W. Li, and I.S. Jawahir, 2009, Surface integrity characterization and prediction in machining of hardened and difficult-to-machine alloys: a state-of-art research review and analysis, Machining Science and Technology, 13, 437-470.

Guerville, L., and J. Vigneau, 2002. Influence of machining conditions on residual stresses. Metal cutting and high speed machining, edited by D. Dudzinski, A. Molinari and H. Schulz, Kluwer Academic Plenum Publishers, pp. 201-210. 
Jeong, Y.H., and D.W. Cho, 2002. Estimating cutting force from rotating and stationary feed motor currents on a milling machine. International Journal of Machine Tools and Manufacture. 42, 1559-1566.

Kamata, Y., Obikawa, T., 2007. High speed MQL finish-turning of Inconel 718 with different coated tools. Journal of Material Processing Technology. 192-193, 281-286.

Kishawy, H.A., and M.A. Elbestawi, 1999. Effects of process parameters on material side flow during hard turning. International Journal of Machine Tools and Manufacture. 39, 10171030 .

Li, X.,. S.K. Tso, 1999. Drill wear monitoring based on current signals, Wear. 231, 172-178.

Ng, E.G., S.L. Soo, C. Sage, R.C. Dewes, R. Dewes, and D.K. Aspinwall, 2002. High speed ball nose end milling of Inconel 718 with variable tool geometry, experimental and finite element analysis, edited by D. Dudzinski, A. Molinari and H. Schulz, Metal Cutting and High Speed Machining, Kluwer Academic Plenum Publishers, pp. 191-200.

Outeiro, J.C., J.C. Pina, R. M'Saoubi, F. Pusavec, and I.S. Jawahir, 2008. Analysis of residual stresses induced by dry turning of difficult-to-machine Materials. CIRP Annals Manufacturing Technology. 57, 77-80.

Pawade, R.S., Joshi S.Suhas, and P.K. Brahmankar, 2008. Effect of machining parameters and cutting edge geometry on surface of high speed turned Inconel 718. International Journal of Machine tools and Manufacture. 48, 15-28.

Schlauer, C., R.L Peng, and M. Odén, 2002. Residual stresses in a nickel-based superalloy introduced by turning. Materials Science Forum, Vol. 404 - 407, pp. 173-178

Sharman, A.R.C., J.I. Hugues, and K. Ridgway, 2006. An analysis of the residual stresses generated in Inconel 718 when turning. Journal of Processing Technology. 173, 359-367.

Sharman, A.R.C., J.I. Hugues, K. Ridgway, 2008. Surface integrity and tool life when turning Inconel 718 using ultra-high pressure and flood coolant systems. Journal of Engineering Manufacture. 222, 653-664. 